\title{
Ultrastructural Investigation of Nerve Regeneration in Vivo
}

\section{-Comparison with in Vitro Neurite Formation-}

\author{
Hiroshi K. INOUE and Lars OLSON* \\ Department of Neurosurgery, Gunma University School of Medicine, Maebashi; \\ ${ }^{*}$ Department of Histology and Neurobiology, Karolinska Institute, Stockholm, Sweden
}

\begin{abstract}
The process of regencration of rat dorsal root ganglion cells was investigated by scanning and transmission electron microscopy and compared with the process of in vitro neurite formation. After disruption of the granular reticulum, numerous microtubules appeared in the perinuclear cytoplasm. Many thin, regenerating nerve fibers were found at the suture line adjacent to collagen fibers. Subsequently, the number of cytoplasmic neurofilament bundles increased and many of the regenerated nerves attached to the suture line. By the eighth week after experimental injury, the granular reticulum had reconstituted in the cytoplasm and the regenerated nerves resembled those of control animals, although the fiber arrangement was somewhat irregular. The process was almost identical to that of in vitro neurite formation, although the time course was much slower. Structural proteins, such as actin, tubulin, and neurofilament triplet, appeared to form similarly in neuronal regeneration and in vitro neurite formation. The results also suggest that microtubules are essential for nerve regeneration as well as neurite formation and that components of the neuronal microenvironment, such as collagen fibers and migrating cells, play crucial roles in nerve regeneration.
\end{abstract}

Key words: nerve regeneration, neuron ultrastructure, structural protein, microtubules

\section{Introduction}

Regeneration of nerve fibers ${ }^{16,18,19,36,53)}$ and their cell bodies ${ }^{6,17,40,42)}$ has been extensively investigated, in various models and with different techniques. The mechanism of nerve regeneration has been partially elucidated at the molecular level. ${ }^{27,54)}$ Studies involving culture and transplantation techniques $^{2,5,21,22,29,32,39)}$ have made possible investigation of central nervous system plasticity ${ }^{4,7,15,50)}$ and regeneration, ${ }^{14,24,28,49,51)}$ and also application of peripheral nerve grafts in brain and spinal cord. ${ }^{1,10-12,37,45,47)}$ However, the mechanism of nerve regeneration is not yet clear. Earlier, in an attempt to better understand this process, we examined neurite formation in culture. ${ }^{21)}$ In the study reported here, we examined regeneration of dorsal root ganglion cells in vivo and compared these findings with those of our in vitro study. As in that investigation, regenerating nerve

Received March 14, 1989;

Accepted June 7, 1989 fibers and cell bodies were observed serially by electron microscopy.

\section{Materials and Methods}

Male Wistar rats weighing $300-400 \mathrm{gm}$ were anesthetized by intraperitoneal injection of $4 \mathrm{mg} /$ $100 \mathrm{gm}$ pentobarbital. The sciatic nerve was transected at mid-thigh and the proximal and distal nerve stumps were sutured epineurally with 11-0 nylon monofilament under the operating microscope. At 3, 5, 7, 10, 14, 28, and 56 days after this procedure, rats were irrigated with Ringer's solution and perfused with a $2.5 \%$ glutaraldehyde solution. The sciatic nerve and L4, L5 dorsal root ganglia were excised and stored in a $1 \%$ glutaraldehyde, $3.5 \%$ formaldehyde solution at $4^{\circ} \mathrm{C}$. The sciatic nerve was then cut longitudinally at the point of the suture line and postfixed with $2 \%$ osmium tetroxide. After dehydration, specimens were dried in a critical point dryer and coated with platinum for scanning elec- 
tron microscopy (SEM). For transmission electron microscopy (TEM), the specimens were postfixed with osmium and embedded in Epon. Cultured neurons obtained from dorsal root ganglia of newborn rats were processed in the same way for SEM and TEM. Details of these methods, including the culture technique, were described previously. ${ }^{21)}$ In brief, dissociated neurons were seeded on polyornithinecoated glass cover slips and cultured with gliomaconditioned medium containing $5-10 \%$ fetal calf serum. The culture was maintained at $37^{\circ} \mathrm{C}$ in a $\mathrm{CO}_{2}$ incubator. The cultured neurons were fixed with $2.5 \%$ glutaraldehyde solution and postfixed with $1 \%$ osmium tetroxide. After dehydration, the cells were dried and coated with platinum for SEM. For TEM the cells were embedded in Epon and the cover slips were removed with a $56 \%$ solution of hydrofluoric acid. Of the several types of neuron in the ganglia, ${ }^{43,48)}$ we focused on the changes of large neurons.

\section{Results}

\section{Sciatic nerve changes at the suture line}

Control sciatic nerve consisted of regularly arranged nerve fibers and a small amount of collagen fibers. Collagen fibers were attached to the nerve fibers and were also present in the spaces between nerve fibers (Fig. 1A). Three days postoperatively, the cut ends of the myelin sheaths were identified as vacant tubules interspersed with collagen fibers. After 5 days, the suture line was filled with many round cells and irregularly arranged collagen fibers.
The cut ends of the nerve sheath were also covered with these materials (Fig. 1B). After 7 days, abundant collagen fibers were found in the sutured space, covering many of the round cells (Fig. 1C). Both proximal and distal nerve sheaths exhibited irregularities, such as varicosities near the suture line. After 10 days, the proximal sheaths appeared smooth and many thin nerve fibers were observed at the point of transection (Fig. 1D). The surfaces of the distal sheaths, however, were still irregular. Two weeks postoperatively, the gap between the cut ends had completely disappeared and the area was filled with numerous regenerated nerves and collagen fibers. Four weeks postoperatively, regenerating nerves of various sizes were abundant, and migrant round cells were not seen. There were fewer collagen fibers and they were connected by small, spherical structures. By 8 weeks, the nerve fibers and collagen fibers appeared identical to those of control specimens, although their arrangement was somewhat irregular.

\section{In vivo cell body changes}

Examination of large neurons in the dorsal root ganglia 3 days postoperatively revealed perinuclear disruption of the granular endoplasmic reticulum and dissociation of ribosomes from their membranes. Multivesicular and dense bodies were sometimes observed (Fig. 2A, B). After 5 days, disruption of the granular reticulum had progressed to the peripheral regions and small Golgi complexes were occasionally seen. Seven days postoperatively, many microtubules were observed in the perinuclear
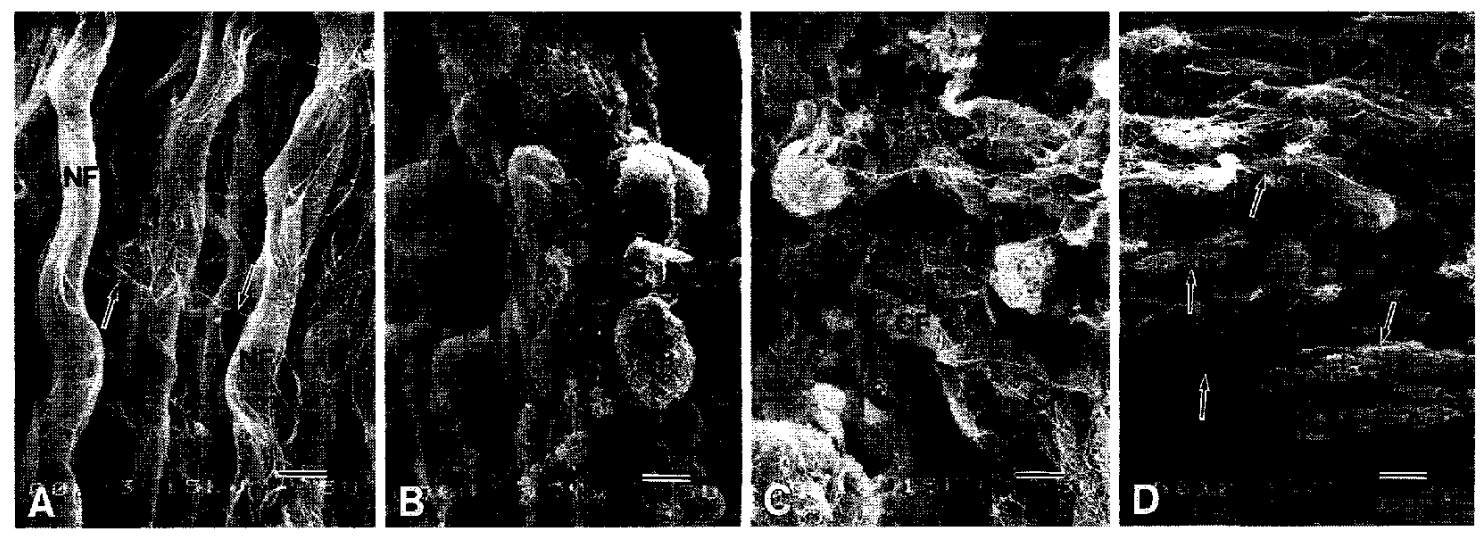

Fig. 1 Scanning electron micrographs of sciatic nerves. A: A normal sciatic nerve with regularly arranged nerve fibers (NF) interspersed with collagen fibers (arrows). B: A sutured sciatic nerve on postoperative day 5 . The gap at the suture line is filled with migrant round cells $(\mathrm{RC})$ and irregularly arranged collagen fibers. C: At day 7 , the wound area is occupied by abundant collagen fibers (CF), which cover the migrant cells. D: Many thin, new nerve fibers (arrows) are present at the suture line after 10 days. Bars $=5 \mu \mathrm{m}$. 


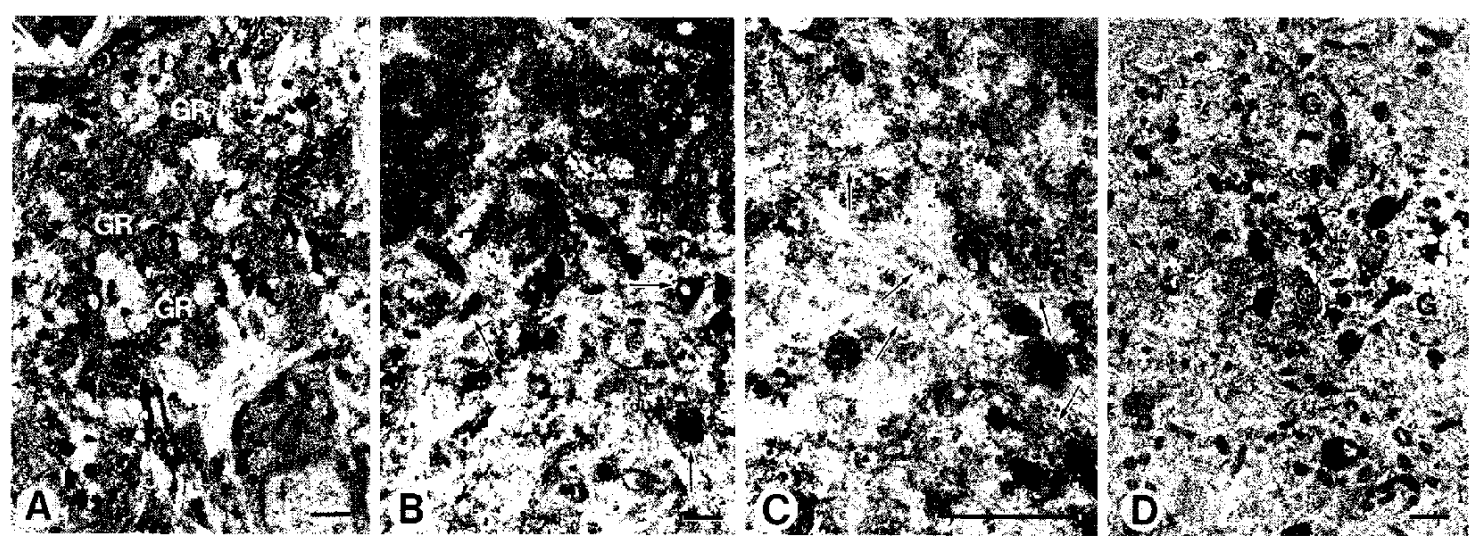

Fig. 2 Transmission electron micrographs of dorsal root ganglia. A: A normal large neuron of the dorsal root ganglion, containing well organized granular reticulum (GR). B: A ganglion showing disruption of granular reticulum and multivesicular and dense bodies (arrows) in the cytoplasm 3 days after injury. C: Many microtubules (arrows) are present in the perinuclear region after 7 days. D: Numerous small Golgi complexes (G) are also seen in the cytoplasm 7 days after injury. Bars $=1 \mu \mathrm{m}$.

region (Fig. 2C) and the number of small Golgi complexes appeared to have increased (Fig. 2D). Neurofilament bundles were somewhat irregular and not abundant. After 10 days, microtubules appeared infrequently. Two weeks postoperatively, neurofilaments were numerous and distributed throughout the cytoplasm. By 4-6 weeks postoperatively, the granular endoplasmic reticulum had reconstituted at the periphery of the cell and bundles of neurofilaments had become regular and clear. By week 8 , the granular reticulum and the arrangement of neurofilaments had returned to normal, but microtubules and multivesicular bodies were sometimes still found.

\section{Comparison with the process of neurite forma- tion in vitro}

The process of in vivo nerve regeneration was almost identical to that of neurite formation in culture, ${ }^{21)}$ although the time course of the former was longer than that of the latter. The results are summarized in Table 1.

\section{Discussion}

Many electron microscopic studies have revealed in detail the changes that occur during axonal regeneration $^{18,19,36,53)}$ and elucidated the importance of axonal transport in nerve regeneration. ${ }^{16,25)}$ In the peripheral nervous system, as opposed to the central nervous

Table 1 Comparison of nerve regeneration in vivo and neurite formation in vitro

\begin{tabular}{|c|c|c|c|c|c|}
\hline \multicolumn{3}{|c|}{ Nerve regeneration (in vivo) } & \multicolumn{3}{|c|}{ Neurite formation (in vitro) ${ }^{213}$} \\
\hline $\begin{array}{l}\text { Time } \\
\text { (days) }\end{array}$ & Nerve & Cell body & Neurite & Cell body & $\begin{array}{c}\text { Time } \\
\text { (hours) }\end{array}$ \\
\hline 3 & vacant space & $\begin{array}{l}\text { disruption of } \\
\text { granular reticulum, } \\
\text { vesicular bodies }\end{array}$ & $\begin{array}{l}\text { microspike } \\
\text { (stages 1-2) }\end{array}$ & $\begin{array}{l}\text { disruption of } \\
\text { granular reticulum }\end{array}$ & \\
\hline 5 & migrant cells & small Golgi complexes & veil (stage 3 ) & Golgi complexes & 2 \\
\hline 7 & collagen fibers & microtubules & $\begin{array}{l}\text { growth cone } \\
\text { (stage 4) }\end{array}$ & microtubules & $3-4$ \\
\hline 10 & regenerating fibers & & $\begin{array}{l}\text { neurite elongation } \\
\text { (stage 5) }\end{array}$ & & 8 \\
\hline 14 & & neurofilaments & & neurofilaments & \\
\hline $30-60$ & normalization & $\begin{array}{l}\text { reorganized } \\
\text { granular reticulum }\end{array}$ & $\begin{array}{l}\text { network of neurite } \\
\text { (stage 6) }\end{array}$ & $\begin{array}{l}\text { reorganized } \\
\text { granular reticulum }\end{array}$ & $24-48$ \\
\hline
\end{tabular}


system, the role of the basal lamina and Schwann cells has been emphasized. ${ }^{3,20,31,41)}$ In the search for a good model of nerve regeneration, silicone and bioresorbable tubes have recently been applied, ${ }^{9,23,24,33)}$ and neurite-promoting factors in the tubes have been examined by bioassay as well as by measurement of the activity of the nerve extracts. ${ }^{30,44)}$ In addition, new clinical suturing and grafting methods are under development. ${ }^{13,34)}$

In this study, using SEM, we examined regenerating nerve fibers in three dimensions and compared the changes to neurite formation in culture. Our results support those of other investigators. In addition, we found marked early changes in collagen fibers and migrating round cells at the suture line, which may be important in nerve regeneration, at least in the initial phase, in terms of mechanical support and promotion of regrowth. In the culture system, we did not detect large growth cones in the sciatic nerve. This is true of other culture systems involving the use of collagen, ${ }^{38)}$ so that the shape and size of growth cones may be influenced by collagen fibers in vivo as well.

Ultrastructural changes in ganglia have also been observed in many models of nerve regeneration..$^{6,17,40,42)}$ Disorganization of granular reticulum and proliferation of free polyribosomes suggests an increase in the synthesis and turnover of ribosomal ribonucleic acid. Changes in Golgi complexes and agranular reticulum may support expansion of the membrane. The increase in microtubules and neurofilaments indicates accelerated polymerization and assembly and suggests axonal elongation. Our results are similar to those previously reported; the time required for regeneration, however, appears to depend on the model used. Since we examined axons and cell bodies in the same rats, we were able to observe the temporal relationship between axonal and cell body changes. Several mechanisms for the initiation of cell body changes have been proposed, including electrophysiological, chemical, pharmacological, and physical processes. ${ }^{8,46)}$ After initiation, we found a dramatic increase in the number of microtubules during both in vivo nerve regrowth and in vitro neurite development. This strongly suggests that microtubules are essential for nerve regrowth and elongation, as we noted previously. ${ }^{21)}$

The sequence of neurite formation or regeneration can be readily observed in culture systems. ${ }^{52)}$ Also, the effects of nerve growth factor and similar substances are easily detected, so that new substances may be tested for possible clinical use. Furthermore, study of culture systems contributes to the understanding of the basic processes and mechanisms of nerve regeneration. ${ }^{5,29,32)}$ Recently, these mechanisms have been studied at the molecular level ${ }^{54)}$ as well as in a culture system. ${ }^{27)}$

Using our culture system, we found that neurons undergo dramatic changes during neurite formation, and we were able to divide the process into six stages. As mentioned, we concluded that microtubules are essential for initiation and elongation of neurites. ${ }^{21)}$ During microspike and veil formation in stages $1-3$, changes took place in the granular reticulum and Golgi complexes in the cell body. Microfilaments and agranular reticulum were present in the microspike and the veil. Since actin and membranous materials are thought to be important in neuronal surface changes, synthesis and polymerization of actin may increase, and the membrane may expand, in this stage. In stages 4 and 5 (growth cone formation and neurite elongation), microtubules proliferated, probably as a result of tubulin and synthesis polymerization. In stage 6, neurofilaments, granular reticulum, and other organelles were arranged regularly in the cytoplasm.

The process of sciatic nerve regeneration was almost identical to that of neurite formation, except that the time course of the former was much longer. The changes from days 3 to 5 in nerve regeneration roughly corresponded to stages $1-3$ in culture. During days $7-10$, in vivo microtubule formation and nerve regrowth resembled the events of stage 4 in culture. Weeks 2-8 in vivo were similar to stages 5-6 in culture and consisted mainly of reorganization. As in the culture system, in vivo process seems to progress from actin filaments and membranous materials to microtubules and then neurofilaments. These results correspond to the findings obtained with radiolabelling techniques in studies of axonal transport of structural proteins, actin, tubulin, and neurofilament triplet in regenerating nerves. ${ }^{26,35)}$

Figure 3 illustrates the process of nerve regeneration and neurite formation, as indicated by our results. After axonal injury, free polyribosomes proliferate in the cell body and actin may be produced. The membrane expands at almost the same time. The injured axon tip forms fine cell process, microvilli, and protrusions, which are composed of microfilaments and agranular reticulum. Subsequently, tubulin may be synthesized in the cytoplasm and then polymerized. Many microtubules appear in the cell body and nerve fibers regrow at the tip of the injured axon, forming the growth cone. Later, neurofilament triplets may form, appearing as neurofilaments in the elongating axons. This is a model of sensory nerve regeneration; some differences may exist in other types of neurons. However, 


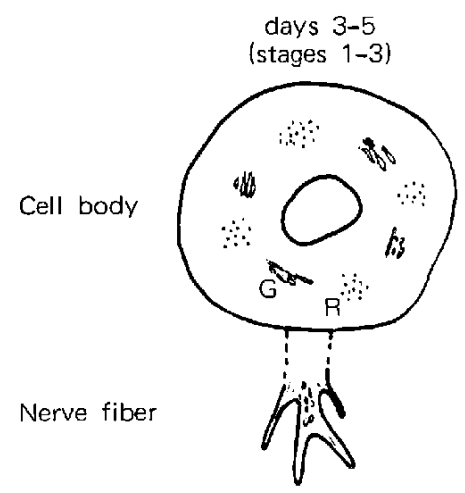

Structure

Molecule

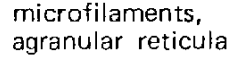

actin

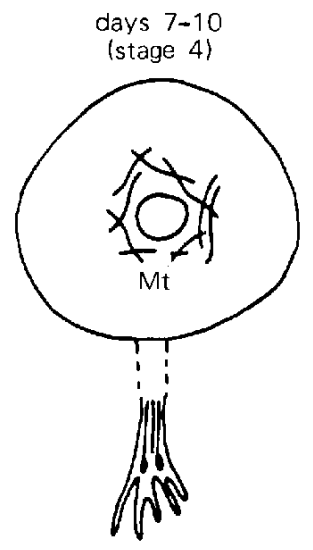

microtubules, mitochondria

tubulin

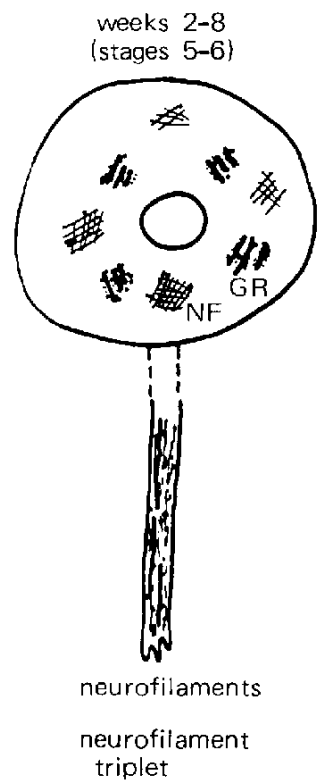

Fig. 3 Diagrammatic representation of nerve regeneration and neurite formation. Changes in organelles in the cell body and growing nerve fibers are shown, as well as nerve structures related to structural proteins. G: Golgi complex, R: ribosomes, Mt: microtubules, NF: neurofilaments, GR: granular reticulum.

understanding this process in the peripheral nervous system will contribute to our knowledge of regeneration in the central nervous system.

In conclusion, these results indicate that nerve regeneration in vivo is an orderly process identical to that of neurite formation in vitro and that structural proteins, such as actin, tubulin, and the neurofilament triplet, may be synthesized in the same way during nerve regeneration and neurite formation. Microtubules appear to be essential for nerve growth both in vitro and in vivo, and certain other components of the neuronal microenvironment, such as collagen fibers and migrating cells, also may play crucial roles in nerve regeneration.

\section{Acknowledgments}

This work was supported by Grants-in Aid for Scientific Research from the Ministry of Education, Science and Culture of Japan.

The authors thank Mamiko Machida, Mitsue Maniwa, and Carina Ohlsson for technical assistance, and Ida Engqvist for expert typing and secretarial help.

\section{References}

1) Aguayo AJ, David S, Richardson PM, Bray GM:
Axonal elongation in peripheral and central nervous system transplants, in Fedoroff S, Hertz L (eds): Advances in Cellular Neurobiology. New York, Academic, 1982, pp 215-234

2) Bernstein JJ, Underberger D, Hoovler D: Transplantation of fetal central nervous system into the adult spinal cord: A possible aid to regeneration, in Gilad G, Kreutzberg G, Gorio A (eds): Processes of Recovery from Neural Trauma. Berlin, Springer, 1986, pp 326-332

3) Bignami A, Chi NH, Dahl D: Laminin in rat sciatic nerve undergoing wallerian degeneration. $J$ Neuropathol Exp Neurol 43: 94-103, 1984

4) Björklund A, Stenevi U: Regeneration of monoaminergic and cholinergic neurons in the mammalian central nervous system. Physiol Rev 59: 62-101, 1979

5) Bunge RP: Contributions of tissue culture studies to our understanding of basic processes in peripheral nerve regeneration, in Gorio A, Millesi $\mathrm{H}$, Mingrino S (eds): Posttraumatic Peripheral Nerve Regeneration. New York, Raven, 1981, pp 105-113

6) Byers MR: Chromatolysis in a pair of identifiable metathoracic neurons in the cockroach, Diploptera punctata. Tissue Cell 2: 255-279, 1970

7) Cotman CW, Nieto-Sampedro M: Cell biology of the synaptic plasticity. Science 225: 1287-1293, 1984

8) Cragg BG: What is the signal for chromatolysis? Brain Res 23: 1-21, 1970

9) da Silva C, Madison R, Dikkes P, Chiu T, Sidman RL: An in vivo model to quantify motor and sensory 
peripheral nerve regeneration using bioresorbable nerve guide tubes. Brain Res 342: 307-315, 1985

10) Dum RP, Salame CG: Growth of medial forebrain bundle axons into peripheral nerve grafts in the rat. Brain Res 372: 198-203, 1986

11) Fernandez E, Pallini R, Maira G, Rossi GF: Peripheral nerve autografts to the injured spinal cord of the rat: An experimental model for the study of spinal cord regeneration. Acta Neurochir (Wien) 78: $57-64,1985$

12) Fernandez E, Pallini R, Minciacchi D, Sbriccoli A: Peripheral nerve autograft to the rat spinal cord: Study on the origin and course of regenerating fibers. Acta Neurochir (Wien) 82: 57-63, 1986

13) Fischer DW, Beggs JL, Kenshalo DL, Shetter AG: Comparative study of microepineurial anastomoses with the use of $\mathrm{CO}_{2}$ laser and suture techniques in rat sciatic nerves: Part 1, surgical technique, nerve action potentials, and morphological studies. Neurosurgery 17: 300-308, 1985

14) Foerster AP: Spontaneous regeneration of cut axons in the adult rat brain. J Comp Neurol 210: 335-356, 1982

15) Freed WJ, DeMedinacelli L, Wyatt RJ: Promoting functional plasticity in the damaged nervous system. Science 227: 1544-1552, 1985

16) Frizell M, Sjöstrand J: Changes in axonal transport in relation to the nerve cell body response during peripheral nerve regeneration, in Gorio A, Millesi $\mathrm{H}$, Mingrino S (eds): Posttraumatic Peripheral Nerve Regeneration. New York, Raven, 1981, pp 35-44

17) Grafstein B, McQuarrie IG: Role of the nerve cell body in axonal regeneration, in Cotman CW (ed): Neuronal Plasticity. New York, Raven, 1978, pp 155-195

18) Hoffman H: Axoplasm, its structure and regeneration, in Windle WF (ed): Regeneration in the Central Nervous System. Springfield, CC Thomas, 1955, pp 112-126

19) Hudson AR, Kline D, Bratton B, Hunter D: Axonal growth at the suture line, in Jewett DL, McCarrol HR (eds): Nerve Repair and Regeneration. St Louis, CV Mosby, 1980, pp 220-226

20) Ide $C$, Tohyama $K$, Yokota R, Nitatori $T$, Onodera $\mathrm{S}$ : Schwann cell basal lamina and nerve regeneration. Brain Res 288: 61-75, 1983

21) Inoue $\mathrm{H}$, Obata $\mathrm{K}$ : Process of neurite formation in culture. As a model for nerve regeneration. Neurol Med Chir (Tokyo) 24: 459-465, 1984

22) Inoue HK, Henschen A, Olson L: Ultrastructure of spinal cord grafts with and without cografts of locus coeruleus in oculo. Exp Neurol 102: 109-120, 1988

23) Jenq $C$, Coggeshall RE: Nerve regeneration through holey silicone tubes. Brain Res 361: 233-241, 1985

24) Knoops B, van den Bosch, de Aguilar P: A new in vivo model to study the influence of the microenvironment in the regeneration of the central nervous system. Brain Res 425: 191-197, 1987

25) Komiya $Y$ : Axonal regeneration in bifurcating axons of rat dorsal root ganglion cells. Exp Neurol 73: 824826,1981

26) Komiya Y: Axonal regeneration and axonal transport. Orthop Traum Surg 25: 1353-1363, 1982

27) Kreutzberg GW: The motoneuron and its microenvironment responding to axotomy, in Das GD, Wallace RB (eds): Neural Transplantation and Regeneration. New York, Springer, 1986, pp 271-276

28) Lasek RJ, McQuarrie IG, Wujek JR: The central nervous system regeneration problem: Neuron and environment, in Gorio A, Millesi $\mathrm{H}$, Mingrino $\mathrm{S}$ (eds): Posttraumatic Peripheral Nerve Regeneration. New York, Raven, 1981, pp 59-70

29) Levi-Montalcini R: Neuronal regeneration in vitro, in Windle WF (ed): Regeneration in the Central Nervous System. Springfield, CC Thomas, 1955, pp 5465

30) Longo FM, Hayman EG, Davis GE, Ruoslahti E, Engvall E, Manthorpe M, Varon S: Neurite-promoting factors and extracellular matrix components accumulating in vivo within nerve regeneration chambers. Brain Res 309: 105-117, 1984

31) Love $S$ : An experimental study of peripheral nerve regeneration after X-irradiation. Brain 106: 39-54, 1983

32) Lubinska L: Axoplasmic streaming in regenerating and in normal nerve fibres, in Singer M, Schadé JP (eds): Mechanisms of Neural Regeneration. Amsterdam, Elsevier, 1964, pp 1-66

33) Lundborg G, Gelberman RH, Longo FM, Powell $\mathrm{HC}$, Varon S: In vivo regeneration of cut nerves encased in silicone tubes. Growth across a sixmillimeter gap. J Neuropathol Exp Neurol 41: 412422,1982

34) Mackinnon SE, Hudson AR, Falk RE, Kline D, Hunter RT: Peripheral nerve allograft: An immunological assessment of pretreatment methods. Neurosurgery 14: 167-171, 1984

35) McQuarrie IG: Structural protein transport in elongating motor axons after sciatic nerve crush. Effect of a conditioning lesion. Neurochemical Pathology 5: 153-164, 1986

36) Morris JH, Hudson AR, Weddell G: A study of degeneration and regeneration in the divided rat sciatic nerve based on electron microscopy. Z Zellforsch 124: 103-130, 1972

37) Munz M, Rasminsky M, Aguayo AJ, Vidal-Sanz M, Devor MG: Functional activity of rat brainstem neurons regenerating axons along peripheral nerve grafts. Brain Res 340: 115-125, 1985

38) Obata $\mathrm{K}$, Inoue $\mathrm{H}$ : Neurite outgrowth from the cerebellum in culture, in Ito $\mathbf{M}(e d)$ : Integrative Control Functions of the Brain, vol 3. Tokyo, Kodansha, 1980, pp 37-39

39) Olson L, Björklund H, Hoffer BJ, Palmer MR, Seiger A: Spinal cord grafts: An intraocular approach to enigmas of nerve growth regulation. Brain Res Bull 9: 519-537, 1982

40) Pannese E: Investigations on the ultrastructural 
changes of the spinal ganglion neurons in the course of axon regeneration and cell hypertrophy. $Z$ Zellforsch 60: 711-740, 1963

41) Pellegrino RG, Spencer PS: Schwann cell mitosis in response to regenerating peripheral axons in vivo. Brain Res 341: 16-25, 1985

42) Price DL, Porter KR: The response of ventral horn neurons to axonal transection. $J$ Cell Biol 53: 24-37, 1972

43) Rambourg A, Clermont $Y$, Beaudet A: Ultrastructural features of six types of neurons in rat dorsal root ganglia. $J$ Neurocytol 12: 47-66, 1983

44) Richardson PM, Ebendal T: Nerve growth activities in rat peripheral nerve. Brain Res 246: 57-64, 1982

45) Richardson PM, McGuinness UM, Aguayo AJ: Peripheral nerve autografts to the rat spinal cord: Studies with axonal tracing methods. Brain Res 237: 147-162, 1982

46) Richardson PM, Verge VMK: The induction of a regenerative propensity in sensory neurons following peripheral axonal injury. $J$ Neurocytol 15: 585-594, 1986

47) So KF, Aguayo AJ: Lengthy regrowth of cut axons from ganglion cells after peripheral nerve transplantation into the retina of adult rats. Brain Res 328: 349 354,1985

48) Sommer E, Kazimierczak J, Droz B: Neuronal subpopulations in the dorsal root ganglion of the mouse as characterized by combination of ultrastructural and cytochemical features. Brain Res 346: $310-326$, 1985

49) Stevenson JA: Growth of retinal ganglion cell axons following optic nerve crush in adult hamsters. Exp Neurol 97: 77-89, 1987

50) Toffano G, Agnati LF, Fuxe KG: The effect of the ganglioside GM1 on neuronal plasticity. Int $J$ Dev Neurosci 4: 97-100, 1986

51) Wendt JS, Ayyad KA: Is there regeneration of cholinergic axons through traumatic scar tissue in adult mammalian brain? Exp Neurol 95: 65-75, 1987

52) Wessells NK, Johnson SR, Nuttall RP: Axon initiation and growth cone regeneration in cultured motor neurons. Exp Cell Res 117: 335-345, 1978

53) Wettstein R, Sotelo R: Electron microscope study on the regenerative process of peripheral nerves of mice. $Z$ Zellforsch 59: 708-730, 1963

54) Willard M, Skene JHP: Molecular events in axonal regeneration, in Nicholls JG (ed): Repair and Regeneration of the Nervous System. Berlin, Springer, 1982, pp 71-89

Address reprint requests to: H.K. Inoue, M.D., Ph.D., Department of Neurosurgery, Gunma University School of Medicine, 3-39 Showa-machi, Maebashi 371, Japan. 